\title{
Evaluation Effects of the Short- and Long-Term Freeze-Thaw Exposure on the Axial Behavior of Concrete-Filled Glass Fiber-Reinforced-Polymer Tubes
}

\author{
Hend El-Zefzafy, Hamdy M. Mohamed, and Radhouane Masmoudi \\ Department of Civil Engineering, University of Sherbrooke, 2500 Université Boulevard, Sherbrooke, QC, Canada J1K 2R1 \\ Correspondence should be addressed to Radhouane Masmoudi; radhouane.masmoudi@usherbrooke.ca
}

Received 10 January 2013; Revised 24 July 2013; Accepted 12 September 2013

Academic Editor: Yanqing Yang

Copyright (C) 2013 Hend El-Zefzafy et al. This is an open access article distributed under the Creative Commons Attribution License, which permits unrestricted use, distribution, and reproduction in any medium, provided the original work is properly cited.

\begin{abstract}
Previous studies have demonstrated the high performance of the concrete-filled fiber-reinforced polymer (FRP) tubes (CFFTs) as a stay-in-place formwork and confining material for concrete structures. However, there are several concerns related to the behavior of CFFT as a protective jacket against harsh environmental effects. The environmental effects such as freeze-thaw cycles and deicing salt solutions may affect materials properties, which may affect the structural response of CFFT members as well. This paper presents the test results of experimental investigation on the durability of short- and long-term behaviors of CFFT members. Test variables included the effect of confining using GFRP tubes, freeze-thaw cycles exposure in salt water, and the number of freezethaw cycles. CFFT cylinders $(150 \times 300 \mathrm{~mm})$ were prepared and exposed to 100 and 300 freeze-thaw cycles in salt water condition. Then, pure axial compression tests were conducted in order to evaluate the performance of specimens due to freeze-thaw exposure, by comparing the stress-strain behavior and their ultimate load capacities. Test results indicated that the confinement using CFFT technique significantly protected the concrete when subjected to freeze-thaw exposure.
\end{abstract}

\section{Introduction}

Corrosion of steel reinforcement causes continual degradation to the worldwide infrastructures, and it has prompted the need for challenges to those involved with reinforced concrete structures. Recently, the use of fiber-reinforced polymer (FRP) tubes as structurally integrated stay-in-place forms for concrete members, such as beams, columns, bridge piers, piles, and fender piles, has emerged as an innovative solution to the corrosion problem. In such integrated systems, the FRP tubes may act as a permanent form, often as a protective jacket for concrete, and especially as external reinforcement in the primary and secondary directions such as for confinement. Furthermore, the use of concrete-filled FRP tubes (CFFTs) technique is predicated on performance attributes linked to their high strength-to-weight ratios, expands the service life of structures, and enhances corrosion resistance, and potentially high durability.
Recently, the CFFT technique has become an adapted structural system for different concrete structures. Therefore, extensive research programs have been conducted to investigate the behavior of concrete columns confined with FRP tubes under pure compression load [1-3]. However, there is a lack of the experimental work regarding the durability effects. Short- and long-term durability of the CFFT is the most important factor needed for CFFT widely implemented application for new constructions. Problems with deteriorated infrastructures in marine settings and cold regions are mainly due to exposure to salt water and subject structures to force water freezing and expanding into ice. Both earlier and more recent studies have revealed that the freeze-thaw cycles can significantly reduce the effects of confinement due to materials degradation. Karbhari and Eckel II [4] reported a reduction of more than $30 \%$ in the ductility of glass FRP-confined concrete as an effect of freeze-thaw cycles combined with moisture. Callery et al. [5] studied the change 
in response of FRP composite wrapped concrete cylinders by using an extensive program of environmental effects on them. The exposed specimens to the low temperature showed higher failure load when compared to specimens kept at room temperature. In dry environment, the freezethaw effect was found to be very low; however, only the hoop strain was affected resulting in more brittle failure mode [6]. Teng et al. [7] investigated the effect of the freeze-thaw cycles thawing process in water on performance of columns wrapped with glass FRP. Little effect on the overall behavior was reported. However, a decrease in both axial and hoop strain capacities had been observed. Saenz and Pantelides [8] investigated the environmental durability issues of concrete circular specimens strengthened using externally applied FRP composites. Standard cylinder specimens were exposed to freeze-thaw cycling in salt water. The result showed that the overall stress-strain behavior of FRP-confined concrete did not change fundamentally, but different levels of exposure significantly affected its absolute stress-strain curve. The radial and axial strains at the point of zero volumetric strain were significantly affected by different levels of exposure. Belarbi and Bae [9] conducted uniaxial compression tests on reinforced concrete columns strengthened with carbonFRP (CFRP) and glass-FRP (GFRP) sheets. The specimens were exposed to a combined environmental cycle such as freeze-thaw cycles, high-temperature cycles, high-humidity cycles, saline solutions, and ultraviolet (UV) radiations in order to evaluate the change of mechanical properties of the test columns. The saline solution had the most deteriorate environmental effect on GFRP-wrapped RC columns among the environmental cycles used, resulting in significant decrease in failure load and ductility, respectively, whereas CFRP-wrapped RC columns exhibited slight decrease in failure load. Toutanji et al. [10] highlighted their observation that the concrete confined with poly(vinyl chloride) PVCFRP hybrid composite was significantly protected than the unconfined concrete when subjected to harsh environmental condition (freeze-thaw and wet-dry). Micelli and Myers [11] investigated the effects of environmental cycles (freeze-thaw cycles, moisture cycles, and high-temperature cycles) and immersion in $\mathrm{NaCl}$ solution on FRP-confined cylinders with GFRP and CFRP composites. It was found that the GFRPwrapped cylinders showed a moderate decrease in ultimate strength and loss in ductility of more than $40 \%$. CFRPconfined specimens, however, did not show a significant decrease in ultimate strength, but cylinders immersed in $\mathrm{NaCl}$ solution lost about $30 \%$ of their axial strain. A recent study by El-Hacha et al. [12] investigated the effects of freezethaw cycles after exposure to heating and cooling cycles on the behavior of concrete cylinder confined with CFRP sheets. The test results indicated that the freezing and thawing reduced the compressive strength.

This paper presents the effects of freeze-thaw cycles combined with those of excessive moisture absorption using the CFFT technique. Writers believe that the experimental findings of this study provide essential relationships that contribute to understand the effect of the freezethaw exposure on the performance of CFFT members. Also, consider an important step toward the CFFT technique to be fully implemented in the field of civil engineering structures.

\section{Experimental Program}

\subsection{Properties of Materials}

2.1.1. FRP Tubes. In this study, GFRP tubes have been used as stay-in-place formwork for the concrete cylinder specimens. The GFRP tubes are fabricated using filament winding technique; E-glass fiber and epoxy resin are utilized for manufacturing these tubes. The internal diameter equals $152 \mathrm{~mm}$. Table 1 presents the dimension and mechanical properties of the GFRP tubes, where $E_{x}$ and $E_{\mathrm{FRP}}$ are the Young moduli in the longitudinal and hoop directions. The laminate theory is used to calculate the Young modulus in the axial and transverse directions based on the mechanical properties of the fiber and resin which were supplied by the manufacture.

2.1.2. Concrete. All specimens were constructed from the same batch of concrete using a ready mix concrete, the concrete mixture was intended to provide normal strength of $30 \mathrm{MPa}$. The maximum size of the coarse aggregates was about $20 \mathrm{~mm}$. Water reducing admixture with super plasticizer was used to increase the workability of the concrete mix. The slump test was done before casting the specimens $(116 \mathrm{~mm})$. Ten plain concrete cylinders $(152 \times$ $305 \mathrm{~mm}$ ) were tested at 28- days under axial load; the average concrete strength for ten cylinders was found to be 33.2 MPa.

2.2. Specimen Details and Preparation. Twenty-four plain concrete and CFFT cylinders $(152 \times 305 \mathrm{~mm})$ were cast. The specimens were divided into two groups; each group consists of twelve specimens: six CFFT cylinders (three for each number of cycles) and six plain concrete unconfined cylinders (three for each number of cycles). The first group was used to preserve virgin samples that were used as reference. Therefore, they were kept at room temperature for a period equivalent to the 100 and/or 300 freeze/thaw cycles, hours. The second group was exposed to 100 and/or 300 freeze/thaw cycling and submerged in salt water to simulate presence of deicing in the infrastructures. The main goal of this set was to evaluate the effect of combination of moisture and freeze-thaw cycling together. Table 2 provides the number of specimens according to how they were utilized in the experiments. The ends of the conditioned cylinders were not exposed by covering it with epoxy to simulate the fact in field applications; columns ends are connected in the superstructure. This is to promote the moisture diffusion of the saturated freeze-thaw exposure only through the FRP tube. Also some specimens were cast with thermocouples inside the concrete core. Before starting the freeze/thaw cycling some of the CFFT specimens were externally instrumented with additional four strain gauges in the hoop and axial directions to capture the strain during the cycling. 
TABLE 1: Dimension and mechanical properties of fiber reinforced polymer tubes.

\begin{tabular}{ccccccccc}
\hline Tube type & $D(\mathrm{~mm})$ & $t_{\mathrm{FRP}}(\mathrm{mm})$ & No. of layers & Stacking sequence & $E_{\mathrm{FRP}}(\mathrm{MPa})$ & $F_{\mathrm{FRPu}}(\mathrm{MPa})$ & $E_{x}(\mathrm{MPa})$ & $F_{x}(\mathrm{MPa})$ \\
\hline$A$ & 152 & 2.65 & 6 & {$[ \pm 60]_{3}$} & $20690^{\S}$ & $345^{\S}$ & $8785^{*}$ & $57.90^{*}$ \\
\hline
\end{tabular}

$E_{x}$ and $E_{\mathrm{FRP}}$ are, respectively, the Young moduli in the longitudinal and hoop directions; $F_{x}$ and $F_{\mathrm{FRPu}}$ are, respectively, the ultimate tensile strengths in the longitudinal and hoop directions; ${ }^{*}$ based on coupon test; ${ }^{{ }^{\circ}}$ based on split-disk test.

TABLE 2: The typical number of test units for each type of the freezethaw cycles.

\begin{tabular}{lccc}
\hline \multirow{2}{*}{ Type of condition } & \multicolumn{3}{c}{ Specimen code } \\
& PCC & CFFT & Total no. \\
\hline Room temperature: Group 1 & 6 & 6 & 12 \\
Freeze-thaw exposure salt water: & & & \\
Group 2 & 3 & 3 & 12 \\
$\quad 100$ cycles & 3 & 3 & \\
$\quad 300$ cycles & 12 & 12 & 24 \\
\hline Total no. of specimens &
\end{tabular}

PCC: plain concrete cylinder.

2.3. Freeze-Thaw Exposure. An isolated wooden tank $(1220 \times$ $1220 \mathrm{~mm}$ ) was fabricated to fit in the environmental chamber. The specimens for saturated freeze-thaw were left in salt water bath and placed in the environmental chamber. The CFFT cylinders were spaced apart from each other and from the bottom of the tank to allow the free circulation of the solution between and around the specimens. The solution level was kept constant throughout the study to avoid a $\mathrm{pH}$ increase which could be due to a solution level decrease and a significant increase of the concentration of the alkaline ions in the solution. Two data acquisition systems were used according to the type to freeze-thaw exposure needed: one to capture the local strain distributions of the CFFT specimens for each condition during cycling; and the second was connected to the concrete core thermocouples to monitor the temperature, which help determining the appropriate program to be used for controlling the environmental chamber, (see Figure 1). The freezing cycles consisted of lowering the temperature in the middle of the saturated concrete specimens from $4.4^{\circ} \mathrm{C}$ to $-17.8^{\circ} \mathrm{C}$ in a period of $16.5 \mathrm{~h}$. The thawing cycles consisted of raising the temperature in the middle of the saturated concrete specimens from $-17.8^{\circ} \mathrm{C}$ to $4.4^{\circ} \mathrm{C}$ in a period of $10.5 \mathrm{~h}$ for the saturated specimens. Those freeze-thaw hours were sufficient to vary the temperature of nonsaturated specimens between $+28^{\circ} \mathrm{C}$ and $-28^{\circ} \mathrm{C}$ as shown in Figure 2. Thus, the specimens underwent one freeze-thaw cycles per 27 hours, rather than in accelerated shorter cycles, for a total of about 112.5 and 337.5 days for 100 and $300 \mathrm{~F} / \mathrm{T}$ cycles, respectively. This procedure which followed to practice this type of exposure was considered to be simulation of winter effect. Also, it conservatively represents a minimum of 68 years of outdoor exposure in order to determinate the resistance of confined cylinders using GFRP tube subjected to repeated cycles of freezing and thawing.

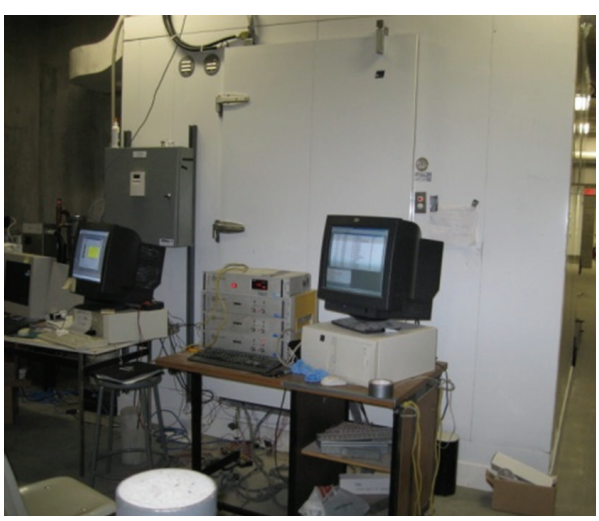

FIGURE 1: Monitoring the specimens inside the chamber during the freeze-thaw cycles.

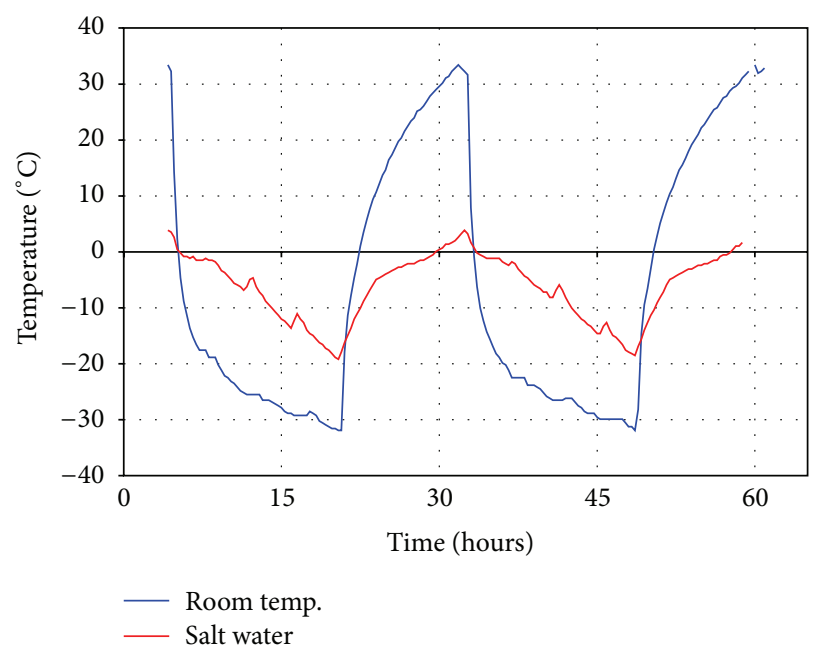

Figure 2: Temperature variation inside the CFFT-conditioned specimens during the freeze-thaw.

2.4. Test Procedure. All specimens were brought to room temperature before being tested. Uniaxial compression tests were conducted until failure. Before testing, two axial and two hoop electrical strain gauges were mounted at the mid height, 180 degree apart, along the hoop direction of the specimens. Strain gauges of $6 \mathrm{~mm}$ length were used to monitor the strain distribution of the GFRP tubes. Also, $30 \mathrm{~mm}$ strain gauges were bonded on the surface of the concrete cylinders.

The axial displacement for each cylinder was measured by two linear variable displacement transducers (LVDTs) 180 degrees apart along the hoop direction of the specimen. 
The LVDTs used have a maximum range of $100 \mathrm{~mm}$ with an accuracy of $0.01 \mathrm{mms}$. All specimens were prepared before the test by a thin layer of the high-strength sulfur capping on the top and bottom surfaces to insure the uniform stress distribution during the test. The specimens were tested using a $6,000 \mathrm{kN}$ capacity FORNEY machine. The CFFT cylinders were set up vertically at the center of loading plates of the machine. The FORNEY machine, strain gauges, and LVDTs were connected by a 20-channel data acquisition system, and the data were recorded every second during the test. The loading rate ranged between 2.0 and $2.50 \mathrm{kN} / \mathrm{s}$, during the test by manually controlling the hydraulic pump. Figures 3(a), 3(b), and 3(c) illustrate the experimental test setup used in this study.

\section{Results and Discussions}

\subsection{Behavior before Testing}

3.1.1. Change in Strain Level due to Freeze-Thaw Cycles. Monitoring results from specimens during the freeze-thaw cycles were plotted into chart showing the variation of the axial strain with time. The effects started during the freeze-thaw cycles. When water in the pores turns into ice and increases in volume by approximately $9 \%$, tensile stresses are induced on the surrounding concrete. Similar pressure would be generated if water was present in spaces between the FRP tube and the confined concrete. However, during the thaw cycles this induced stress was released. Therefore, as illustrated in Figure 4, the freeze-thaw cycling caused the strain to variy up and down due to the expansion and contraction of the concrete core. This could give possible explanation to the higher strain values recorded for specimens exposed to freeze-thaw while submerged in salt water. From careful observation during the freeze-thaw cycles, it should be noted that the unconfined cylinders (plain concrete) exposed to freeze/thaw conditions in saturated state started to show visual signs of deterioration in the concrete after $40 \mathrm{~F} / \mathrm{T}$ cycles.

At the end of the 300 cycles and prior to testing, all the specimens were visually inspected for evidence of degradation in terms of microcracks. Inspection of the specimens indicted that there were noticeable definite differences between the two sets of specimens (the room temperature affect and freeze-thaw exposure). Signs of deterioration in the saturated plain concrete cylinders in salt water after freeze/thaw exposure were reported, rather than specimens kept at room temperature, as illustrated in Figure 5.

3.2. Test Results. Tables 3 and 4 summarize all the test results, in terms of failure load, the corresponding axial stress, and axial and hoop strains. The results also were plotted into charts showing the variation of axial stress with axial strain relationships on the right-hand side and of the axial stress with radial strain relationships on the left-hand side (see Figure 6).
3.2.1. Effect of Confinement: Virgin Specimens. Confinement using GFRP tube showed a large increase in the compressive strength, axial and radial strains in comparison with unconfined specimens, due to the confinement in the radial direction. As Figure 6 depicted, the stress-strain curves are essentially composed of two parts: elastic region and plastic region with a transition zone in between. The initial part of the curve is referred to as the elastic region in which the slop is linearly elastic similar to the behavior of plain concrete and ascends rapidly up to the ultimate unconfined concrete strength. In this region, the elastic radial pressure which exerted by the GFRP tube is negligible, by means that damage of the concrete core has not exceeded the concrete tensile strain capacity yet. During the transition zone, the concrete core exhibits cracks and the core lateral expansion becomes limited by the elastic pressure of the FRP tubes. In this stage, the tube confining started to be fully activated. Thus, the second region to the right of the transition zone, the plastic region, was strongly influenced by the stiffness of the GFRP tube. Therefore, improvement in compressive strength, ductility, and absorption capacity was reported. Also, a sharp transition for CFFT cylinders could be noted between the first and second regions of the stress-strain curve. Table 4 presents the effect of confinement provided by GFRP tubes in comparison with the virgin specimens kept at room temperature, in terms of changes average level of ultimate strength, axial and radial strains. The average strength of the CFFT cylinders was $71.6 \mathrm{MPa}$, representing $115.5 \%$ increase over the unconfined concrete compressive strength of plain cylinders. The average ratio of confined to unconfined concrete strength $\left(f_{c c}^{\prime} / f_{c}^{\prime}\right)$ was 2.16 . As expected, significant enhancement of the strength as well as the ductility for the CFFT cylinders was achieved by confining using the GFRP tube. Also, it can be observed from Figure 6 that at the same stress level, the axial strain of CFFT was always higher than the radial strain. This could be attributed to the high strain capacity of the glass fibers resulting in a significantly larger increase in ultimate hoop strain.

\subsubsection{Effects of Freeze-Thaw Cycles}

Compressive Strength. It is well known that the freeze-thaw cycling affect each of the concrete; the FRP composite; and the CFFT acting as integrated system. Therefore, herein not only the effects of freeze-thaw on the ultimate strength level will be presented, but also the important effects on the damage; failure mechanism and the basis changes on overall behavior will be reviewed. The control plain concrete (unconfined) gave strength of $33.2 \mathrm{MPa}$. The experimental results of the of freeze-thaw effect on the average compressive strength $\left(f_{c}^{\prime}\right)$ were reported in Table 3. A reduction in the compressive strength $\left(f_{c}^{\prime}\right)$ of the unconfined cylinders by 27.5 and $22 \%$ were observed after exposure to 100 and 300 freeze/thaw cycles in salt water, respectively, in comparison with the room temperature specimens. At this point, it should be noted that these reductions occurred although air entrainment concrete was used to minimize the freeze-thaw effect as much as possible. 


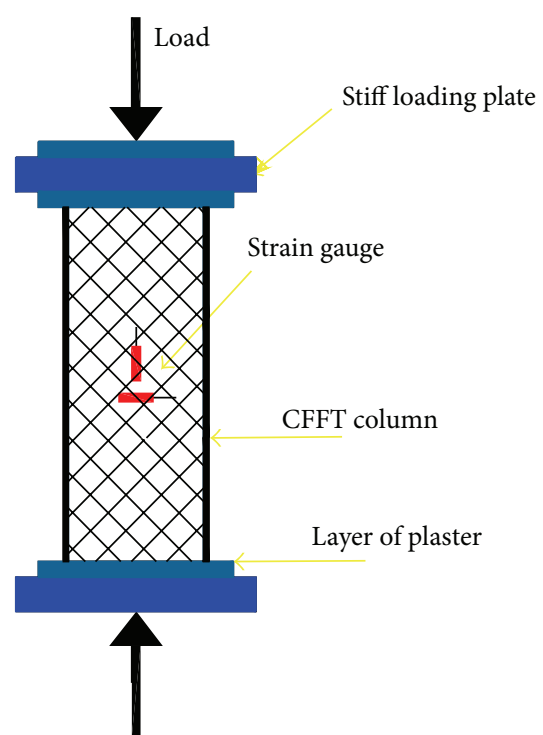

(a) Schematic of the test setup

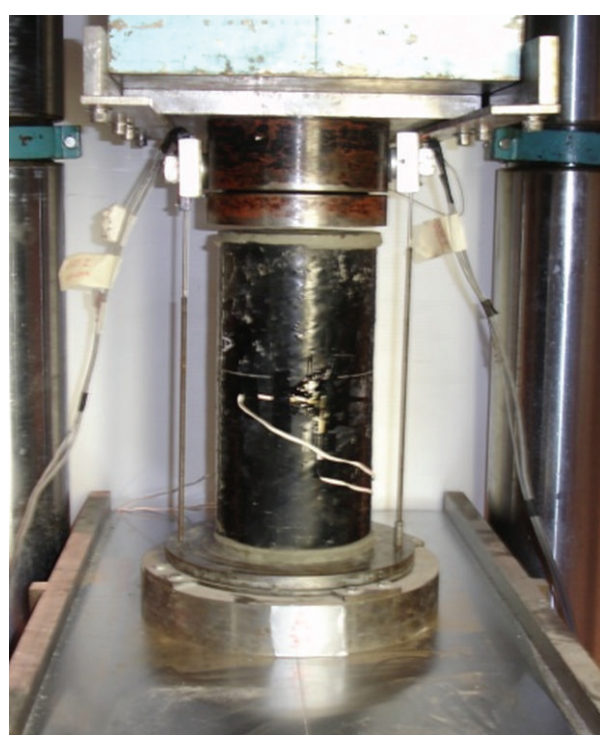

(b) CFFT type A cylinders

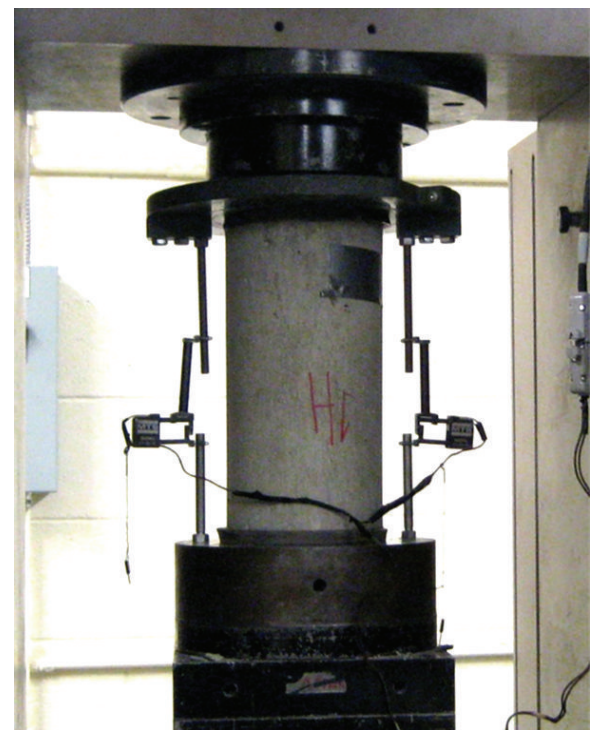

(c) Plain concrete cylinders

FIGURE 3: Schematic and image of the test setup for plain concrete and CFFT cylinders.

Test results for conditioned specimens, in terms of axial compressive strength and ultimate axial and hoop strains, are reported in Table 4 for CFFT specimens, in comparison with the virgin specimens kept at room temperature. Results from axial compression test, after the 100 freeze-thaw exposure, seems to have no effect, indicating slight reduction in the average ultimate compressive strength than the confined specimens kept at room temperature. Figure 7 depicted a comparison between the compressive strength of conditioned and unconditioned specimens. The short-term freeze/thaw exposure in salt water resulted in a slight reduction $(2.9 \%)$ in the average compressive strength of CFFT specimens.

On the other hand, the reduction in the compressive strength reached up to $8.7 \%$ for CFFT specimens, after 300 freeze-thaw cycles in salt water. This could be attributed in large part to two possible reasons: the first is the tendency of the glass fiber, in submerged specimens, to be damaged because of the moisture extract ions from the fiber which in turn leads to degradation of the fiber, manifested in cracks in the fiber surface (Kumar and Gupta [13]); second reason could be probably the plasticization of matrix, induced due to submerging in water, which could make the polymer softer and cause microcraks at the matrix-fiber interface $[13,14]$. In addition to the previously concern, test results give evidence that the further the cycle continues the more the degradation is recorded, resulting in strength reduction. In other words, the level of decrease in strength caused by 300 freeze-thaw cycling is greater than that caused by the $100 \mathrm{~F} / \mathrm{T}$ cycling. This emphasized the deleterious effect of coupled moisture and freeze-thaw cycling. 


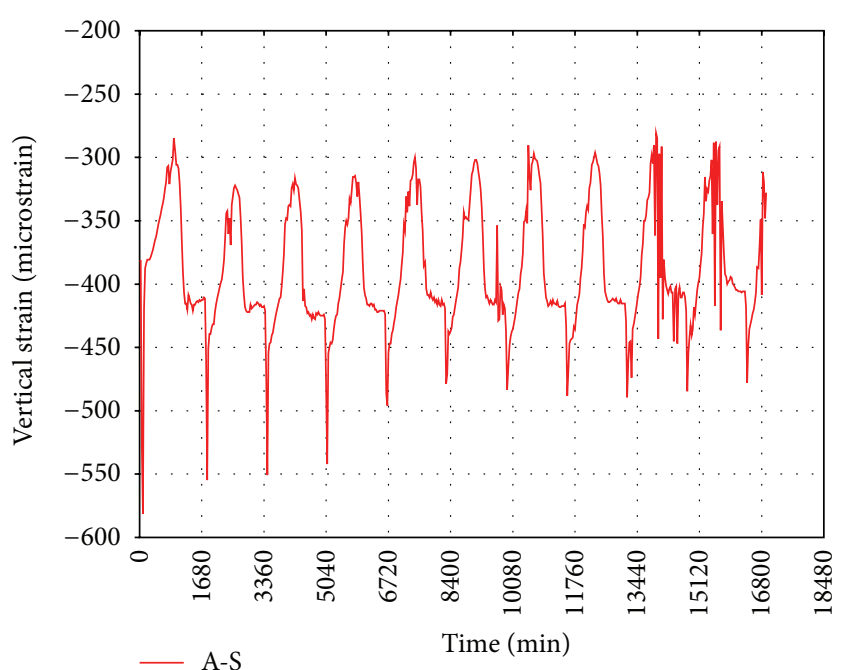

FIGURE 4: The strain variation during the freeze-thaw cycling.

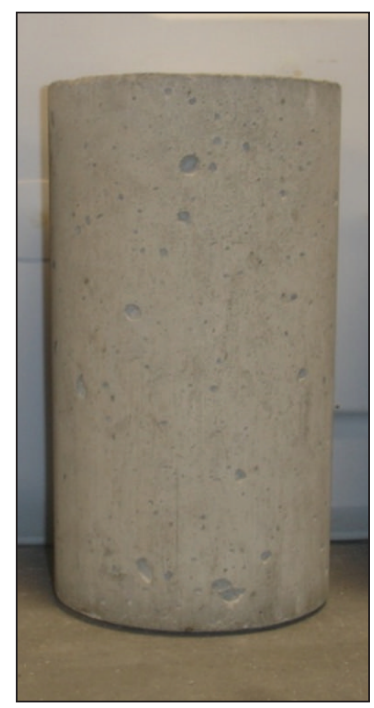

Freeze/thaw in air

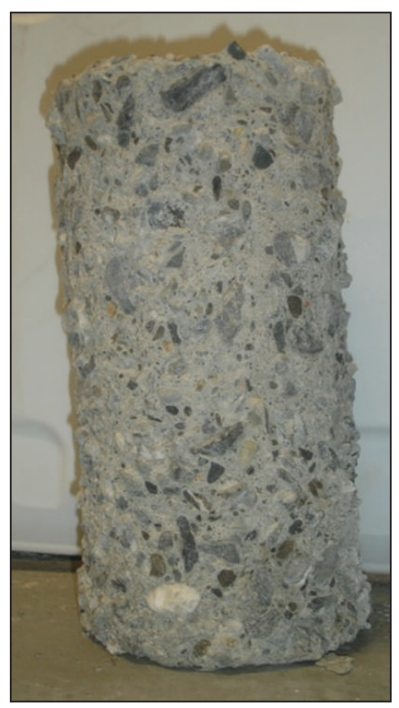

Freeze/thaw in salt water
Figure 5: Signs of degradation of PCC at $300 \mathrm{~F} / \mathrm{T}$ cycles before testing.

TABLE 3: Test results of unconfined concrete cylinders.

\begin{tabular}{lcc}
\hline Plain concrete & Room temperature & $\begin{array}{c}\text { F/T in } \\
\text { Salt water }\end{array}$ \\
\hline Average strength $f_{c}^{\prime}(\mathrm{MPa})$ & & \\
100 F/T cycles & 33.2 & 24.1 \\
$300 \mathrm{~F} / \mathrm{T}$ cycles & 33.2 & 25.9 \\
\hline
\end{tabular}

Hoop and Axial Strains Response. The objective of this section is to understand, based on the experimental evidence, the freeze-thaw effect on the fundamental stress-strain relationships of CFFT specimens. Figures 8 and 9 depict the stressstrain response of CFFT columns that exposed to 100 and $300 \mathrm{~F} / \mathrm{T}$ cycles in comparison with the room temperature

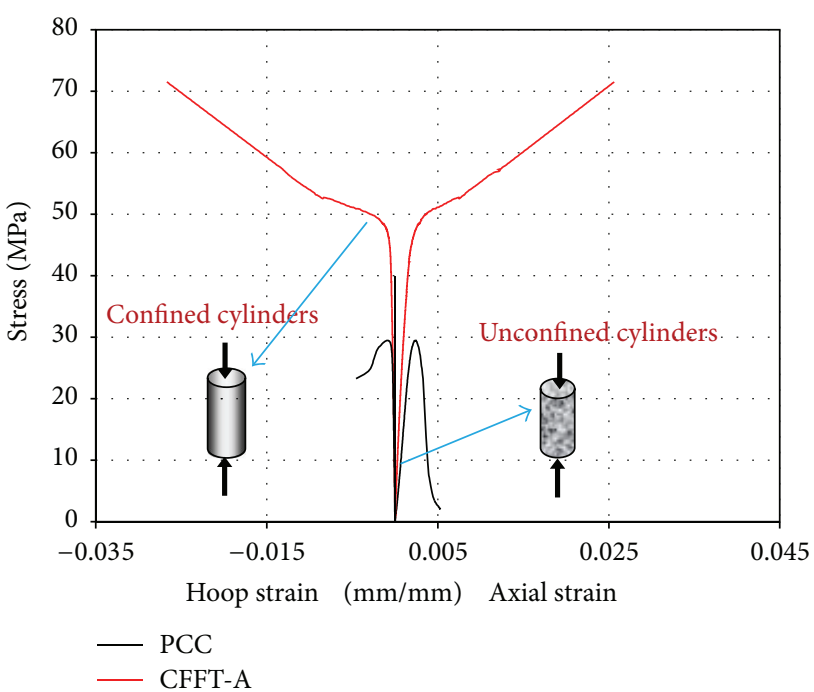

FIgure 6: Typical stress strain curve of PCC and CFFT (Tube A) specimens at room temperature.

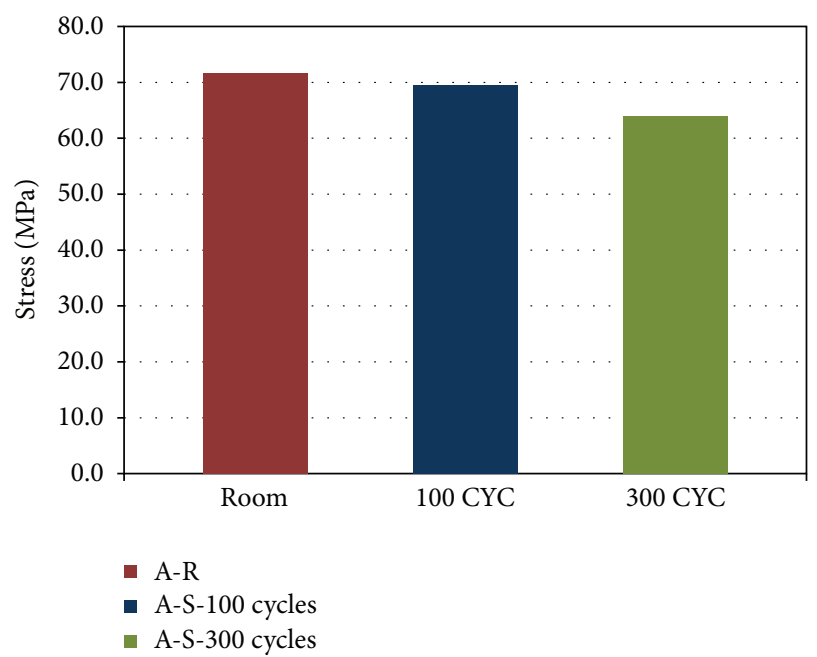

FIgURE 7: Residual compressive stress of conditioned and unconditioned CFFT specimens.

specimens, respectively. Since the FRP is essentially elastic material, thus the kinematic restraint of the concrete is controlled by the amount of deformation given by the FRP tube. At this juncture, it is considerable that the ultimate radial and axial strains of the CFFT specimens were reached when failure or rupture of the FRP tube occurred. This explains why all curves draw a bilinear behavior with the point of change from initial linear response to nonlinearity being seen. Starting the hardening has been attributed to the full confining action of the GFRP tube with microcracking in the concrete core. It is of interest to report that CFFT specimens exposed to 300 freeze-thaw cycles had its change point slightly earlier than the CFFT specimens exposed to 100 freeze-thaw cycles. However, the level of axial strain at 
TABLE 4: Overall response characteristics for confined concrete (CFFT) cylinders.

\begin{tabular}{|c|c|c|c|c|c|c|c|c|}
\hline \multirow{3}{*}{ Specimen code } & \multicolumn{8}{|c|}{ Average failure level } \\
\hline & \multicolumn{4}{|c|}{$100 \mathrm{~F} / \mathrm{T}$ cycles } & \multicolumn{4}{|c|}{$300 \mathrm{~F} / \mathrm{T}$ cycles } \\
\hline & Load kN & $f_{c c}^{\prime}$ strength $(\mathrm{MPa})$ & Axial strain & Radial strain & Load $\mathrm{kN}$ & $f_{c c}^{\prime}$ strength $(\mathrm{MPa})$ & Axial strain & Radial strain \\
\hline \multicolumn{9}{|c|}{ Group 1: room temperature } \\
\hline \multirow{2}{*}{ A-R1 } & \multirow{2}{*}{1297.15} & \multirow{2}{*}{71.5} & 0.028 & 0.026 & \multirow{2}{*}{1306.6} & \multirow{2}{*}{72.0} & 0.030 & 0.022 \\
\hline & & & 0.036 & 0.028 & & & 0.041 & 0.036 \\
\hline \multirow{2}{*}{ A-R2 } & \multirow{2}{*}{1290.1} & \multirow{2}{*}{72.1} & 0.023 & 0.030 & \multirow{2}{*}{1288} & \multirow{2}{*}{71.1} & 0.031 & 0.025 \\
\hline & & & 0.045 & 0.037 & & & 0.037 & 0.035 \\
\hline \multirow{2}{*}{ A-R3 } & \multirow{2}{*}{1311.3} & \multirow{2}{*}{72.3} & 0.035 & 0.027 & \multirow{2}{*}{1216} & \multirow{2}{*}{67} & 0.033 & 0.027 \\
\hline & & & 0.036 & 0.028 & & & 0.034 & 0.029 \\
\hline Average & 1299.52 & 71.6 & 0.034 & 0.029 & 1270.2 & 70 & 0.034 & 0.029 \\
\hline $\mathrm{SD}$ & 10.8 & 0.61 & 0.023 & 0.017 & 47.9 & 2.7 & 0.003 & 0.001 \\
\hline \multicolumn{9}{|c|}{ Group 2: F/T in salt water } \\
\hline \multirow{2}{*}{ A-S1 } & \multirow{2}{*}{1177.41} & \multirow{2}{*}{64.92} & 0.025 & 0.023 & \multirow{2}{*}{1136.7} & \multirow[t]{2}{*}{62.7} & 0.029 & 0.028 \\
\hline & & & 0.035 & 0.031 & & & 0.024 & 0.018 \\
\hline \multirow{2}{*}{ A-S2 } & \multirow{2}{*}{1303.71} & \multirow{2}{*}{71.88} & 0.025 & 0.022 & \multirow{2}{*}{1225.2} & \multirow[t]{2}{*}{67.6} & 0.034 & 0.027 \\
\hline & & & 0.042 & 0.032 & & & 0.029 & 0.027 \\
\hline \multirow{2}{*}{ A-S3 } & \multirow{2}{*}{1306.59} & \multirow{2}{*}{72.04} & 0.030 & 0.027 & 11263 & 61.5 & 0.030 & 0.022 \\
\hline & & & 0.032 & 0.037 & & & 0.019 & 0.020 \\
\hline Average & 1262.57 & 69.61 & 0.031 & 0.029 & 1162.7 & 63.9 & 0.027 & 0.024 \\
\hline SD & 73.76 & 4.07 & 0.007 & 0.006 & 54.3 & 3.2 & 0.005 & 0.004 \\
\hline
\end{tabular}

First letter refers to the type of the tube used in this study. Second letter refers to the type of condition (R: room temperature and S: freeze-thaw exposure in salt water). The third is a number referring to the number of specimens.

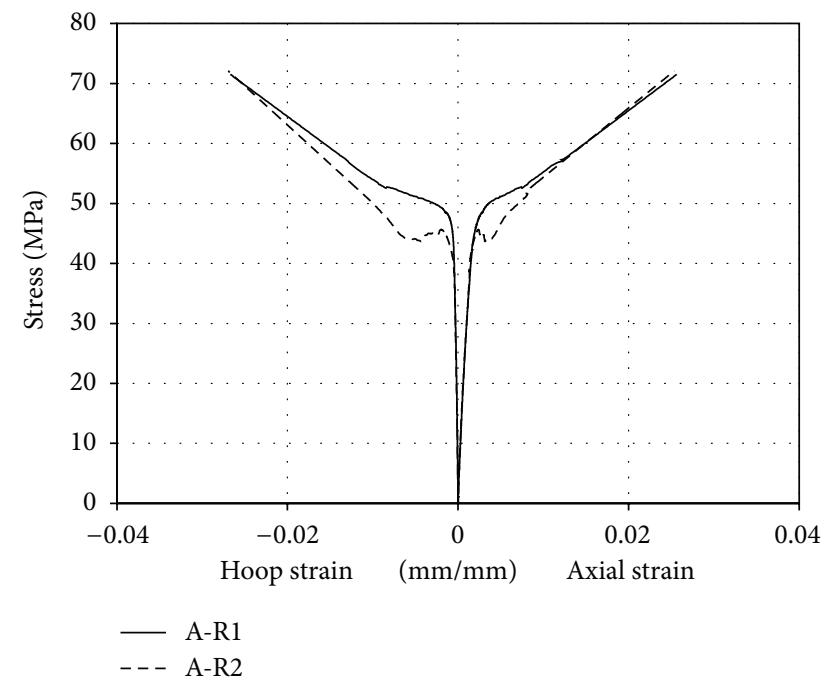

FIGURE 8: Hoop and axial strains of unconditioned (room temperature) CFFT cylinders.

the change point is generally quite lower after the freezethaw exposure in comparison with the room temperature specimens.

Short-term freeze-thaw exposure in salt water, used in this study, resulted in reduction (6.7 and $1.8 \%$ ) in the average ultimate axial and hoop strains of CFFT specimens, respectively. While, the long-term exposure presented in 300 freeze-thaw cycles resulting in a definite effect was evident by significant reduction in terms of changes in the average ultimate level of axial and hoop strains of CFFT specimens, as measured by the lower values reported for exposed specimens. With regard to the freeze-thaw exposure, freezethaw in salt water was the worst case where the reduction reached up to 18.7 and $19.1 \%$ in the average ultimate level of axial and hoop strains, respectively, as presented in Figures 10 and 11. This again is not surprising since the effects of change in properties of the FRP composites and concrete are likely to be affected to a greater extentd as much as freezethaw exposure extended. The reduction in axial strain could be drawback to the increased voids and induced internal damage in the concrete microstructure caused by the freezethaw cycles. Consequently, the accelerated internal damage of the concrete starts early the activation of the FRP tube as previously discussed.

3.3. Failure Mode. Figure 12 shows the failure modes of the conditioned and unconditioned CFFT cylinders. In all cases, careful observation showed that the mode of failure did not change fundamentally with the freeze-thaw exposure. However, more catastrophic failure was observed after freeze-thaw exposure. In general, all specimens failed due to rupture of the GFRP tube at the ultimate radial strain when the confined pressure reached its maximum values. This pressure resulted from the dilation of the concrete core inside the FRP tube. Popping sounds were heard during the early-to-middle stages of loading which were referred to the dilation, microcracking of concrete, and offset of the aggregate. However, FRP tube prevented the concrete in the specimens from spilling. At 


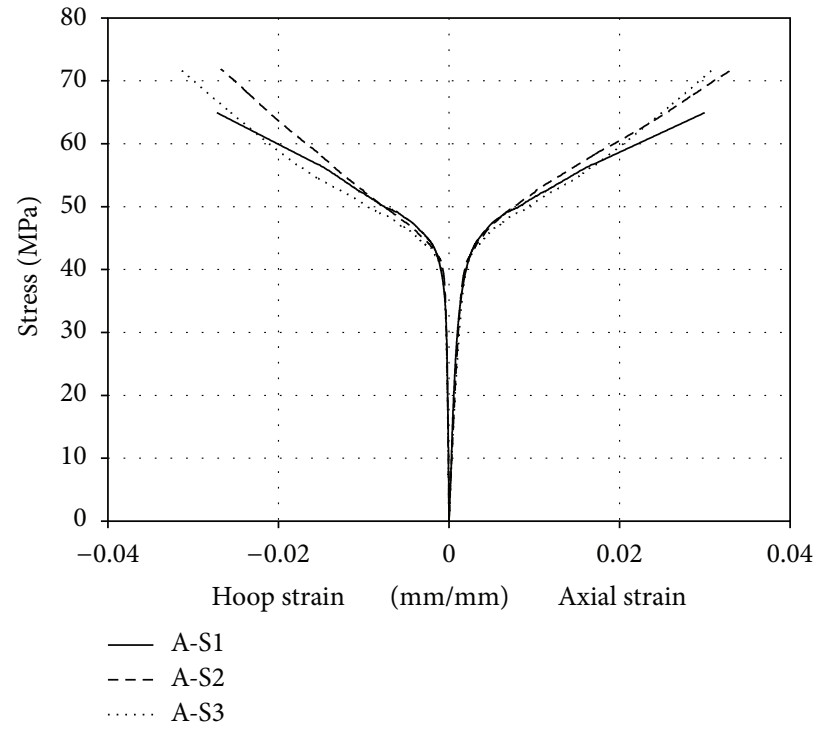

(a) CFFT cylinders exposed to $100 \mathrm{~F} / \mathrm{T}$ cycles

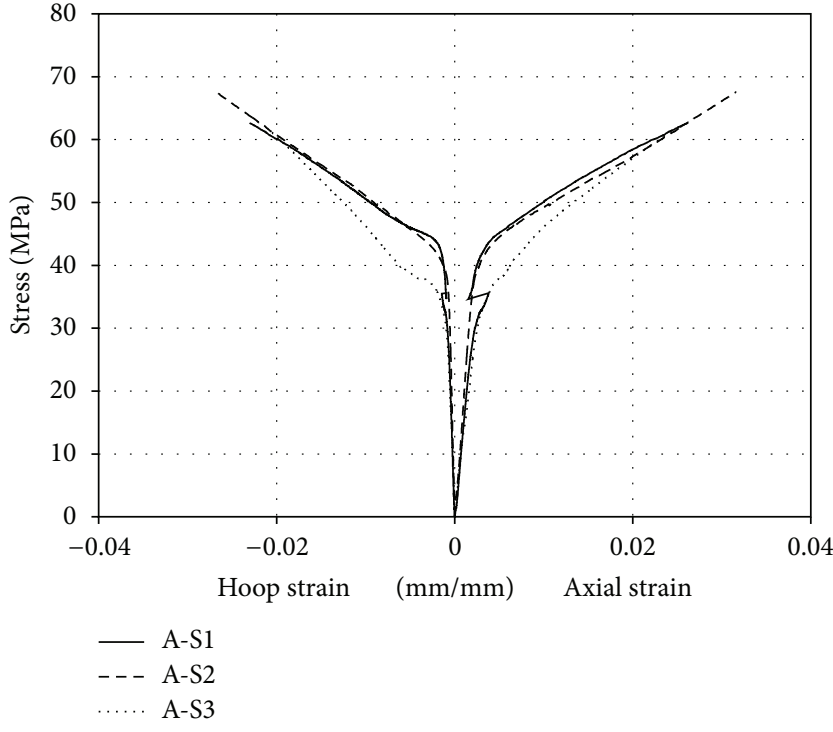

(b) CFFT cylinders exposed to $300 \mathrm{~F} / \mathrm{T}$ cycles

FIGURE 9: Hoop and axial strains of conditioned CFFT cylinders.

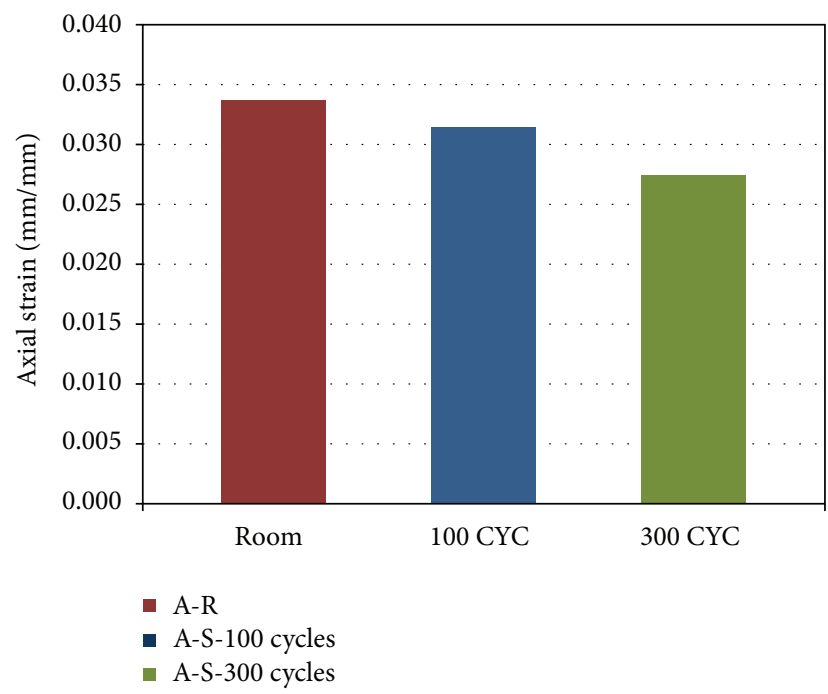

FIGURE 10: Residual axial strain of conditioned and unconditioned CFFT specimens.

this point, it was hypothesized that the stress-strain curve changed slop, and the specimen was able to carry more load. Consequently, at higher levels of confining pressure sounds were heard distinctly and the failure was sudden without much warning. The ultimate failure was very explosive due to rupture of the fibers in GFRP tube, and the concrete fell out of the tube in a crushed state. Thus, one disadvantage of using the FRP tube is the difficulty in predicting when a CFFT specimen is about to fail. The fracture of the tube occurred within total height of the cylinders, initiate from top or bottom and extended to the opposite direction. The shape of the failure was "zigzag" pattern suggesting formation

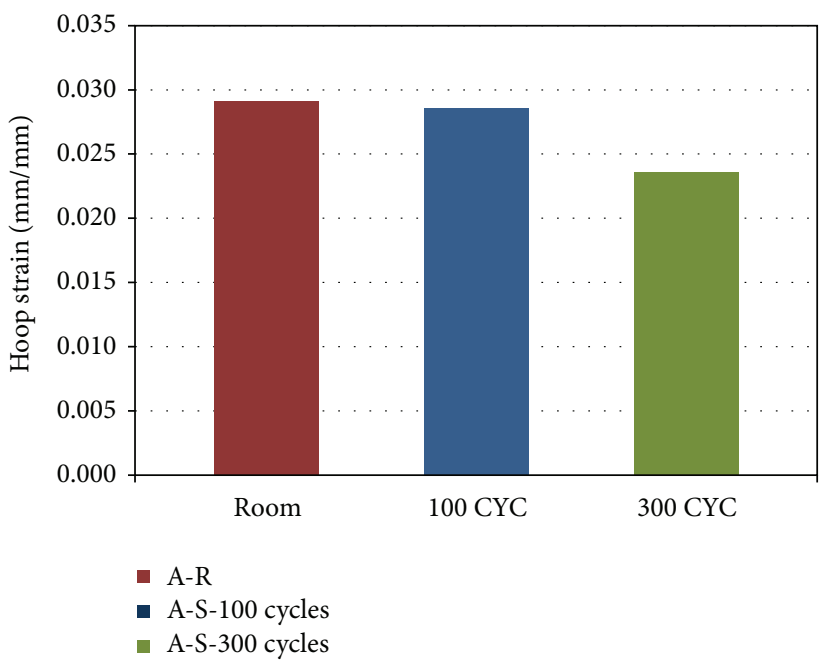

FIGURE 11: Residual hoop strain of conditioned and unconditioned CFFT specimens.

of sequential microcracks parallel to fiber direction. It is noteworthy that the serrated failure pattern was fairly, sharply notched and widespread in CFFT specimens indicative of interlaminate fracture. Visual inspection of the surface failure showed evidence of matrix microcracking, fiber-matrix debonding, and even fiber pullout as a result of freeze-thaw cycling. After $300 \mathrm{~F} / \mathrm{T}$ cycles, this mode of failure is more pronounced, as can be expected under the prolonged cycles.

\section{Summary and Conclusions}

The study herein intended to examine experimentally the short- and long-term effects of freeze-thaw cycling in salt 


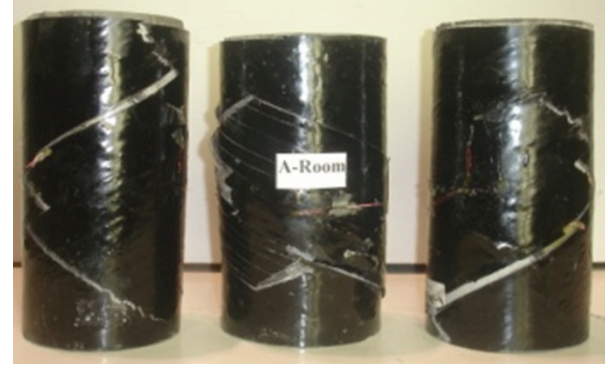

(a) Room Temperature exposure

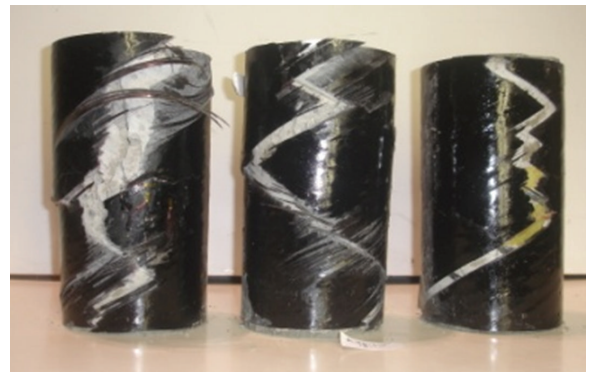

(b) 100 freeze-thaw cycles exposure

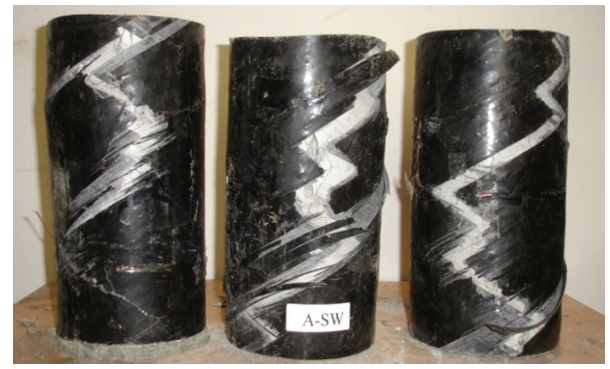

(c) 300 freeze-thaw cycles exposure

FIGURE 12: Failure modes of conditioned and unconditioned CFFT cylinders.

water on the compressive behaviour of concrete-filled GFRP tubes cylinders. In summary, it was found that the confinement using a GFRP tube appear to provide excellent protection against freeze-thaw cycles. Based on the test results so far, the following conclusions are drawn.

(i) The results of this study come in line with others to give experimental evidence that the GFRP tube provided an effective means of protecting the concrete core from severe environmental conditions. Also, significant increases in strength and ductility behavior, in terms of average axial and hoop strain, were achieved for the CFFT cylinders compared to unconfined cylinders.

(ii) Confinement using GFRP tube was found to enhance the compressive strength by up to 2.16 times that of plain concrete which means a $115.7 \%$ increase in the compressive strength over the unconfined cylinders, respectively.

(iii) The plain concrete cylinder (PCC) exposed to 100 freeze-thaw cycles in salt water showed significant reduction in the axial compressive strength (27.5\%). The corresponding reduction was $22 \%$ after 300 freeze-thaw cycles in salt water. Regardless the type of the freeze-thaw cycles, the 100 cycles have almost no effect on the average ultimate compressive strength. However, insignificant decreases $(2.8 \%)$ in the confined compressive strengths of the CFFT cylinders that exposed to freeze-thaw in salt water were observed.

(iv) Significant degradation in the strength properties of CFFT cylinders was reflected by increasing the number of freeze-thaw cycles from 100 to 300 . The reductions in the average ultimate strength, axial and hoop strains were more pronounced (much as 8.7, 18.7, and $19.1 \%$, resp.), for the set exposed to freeze-thaw in salt water. This reduction is attributed to the fiber and fiber-matrix degradation induced by the freeze-thaw cycling in saturated state.

(v) The mode of failure did not change fundamentally with the freeze-thaw exposure. However, more catastrophic failure was observed specially after 300 freezethaw cycles.

\section{Acknowledgments}

The research reported in this paper was partially sponsored by the Natural Sciences and Engineering Research Council of Canada (NSERC). The authors also acknowledge the contribution of the Canadian Foundation for Innovation (CFI) for the infrastructure used to conduct testing. Special thanks to the FRE Composites Inc., QC, Canada, for providing the FRP tubes.

\section{References}

[1] H. Mohamed and R. Masmoudi, "Compressive behavior of reinforced concrete-filled FRP tubes," in FRP Stay-in-Place Forms for Concrete Structures Sessions-ACI Spring Convention 2008, pp. 89-105, March 2008.

[2] H. M. Mohamed and R. Masmoudi, "Axial load capacity of concrete-filled FRP tube columns: Experimental versus theoretical predictions," Journal of Composites for Construction, vol. 14, no. 2, pp. 231-243, 2010.

[3] A. Z. Fam and S. H. Rizkalla, "Flexural behavior of concretefilled fiber-reinforced polymer circular tubes," Journal of Composites for Construction, vol. 6, no. 2, pp. 123-132, 2002.

[4] V. M. Karbhari and D. A. Eckel II, "Effect of cold regions climate on composite jacketed concrete columns," Journal of Cold Regions Engineering, vol. 8, no. 3, pp. 73-86, 1994.

[5] K. Callery, M. F. Green, and J. F. Archibald, "Environmental effects on the behavior of wrapped concrete cylinders," in Proceedings of the 3rd International Conference on Advanced Composite Materials in Bridges and Structure, pp. 759-766, Montreal, Canada, 2000.

[6] V. M. Karbhari, J. Rivera, and P. K. Dutta, "Effect of short-term freeze-thaw cycling on composite confined concrete," Journal of Composites for Construction, vol. 4, no. 4, pp. 191-197, 2000.

[7] M.-H. Teng, E. D. Sotelino, and W.-F. Chen, "Performance evaluation of reinforced concrete bridge columns wrapped 
with fiber reinforced polymers," Journal of Composites for Construction, vol. 7, no. 2, pp. 83-92, 2003.

[8] N. Saenz and C. P. Pantelides, "Short and medium term durability evaluation of FRP-confined circular concrete," Journal of Composites for Construction, vol. 10, no. 3, pp. 244-253, 2006.

[9] A. Belarbi and S.-W. Bae, "An experimental study on the effect of environmental exposures and corrosion on RC columns with FRP composite jackets," Composites Part B, vol. 38, no. 5-6, pp. 674-684, 2007.

[10] H. A. Toutanji, Z. Liangying, and G. J. Isaacs, "Durability studies on concrete columns confined with advanced fibre composites," International Journal of Materials and Product Technology, vol. 28, no. 1-2, pp. 8-28, 2007.

[11] F. Micelli and J. J. Myers, "Durability of FRP-confined concrete," Construction Materials, vol. 161, no. 4, pp. 173-185, 2008.

[12] R. El-Hacha, M. F. Green, and G. R. Wight, "Effect of severe environmental exposures on CFRP wrapped concrete columns," Journal of Composites for Construction, vol. 14, no. 1, pp. 83-93, 2010.

[13] A. Kumar and R. K. Gupta, Fundamentals of Polymers, GrawHill, New York, NY, USA, 1998.

[14] C. L. Schutte, "Environmental durability of glass-fiber composites," Materials Science and Engineering R, vol. 13, no. 7, pp. 265324, 1994. 

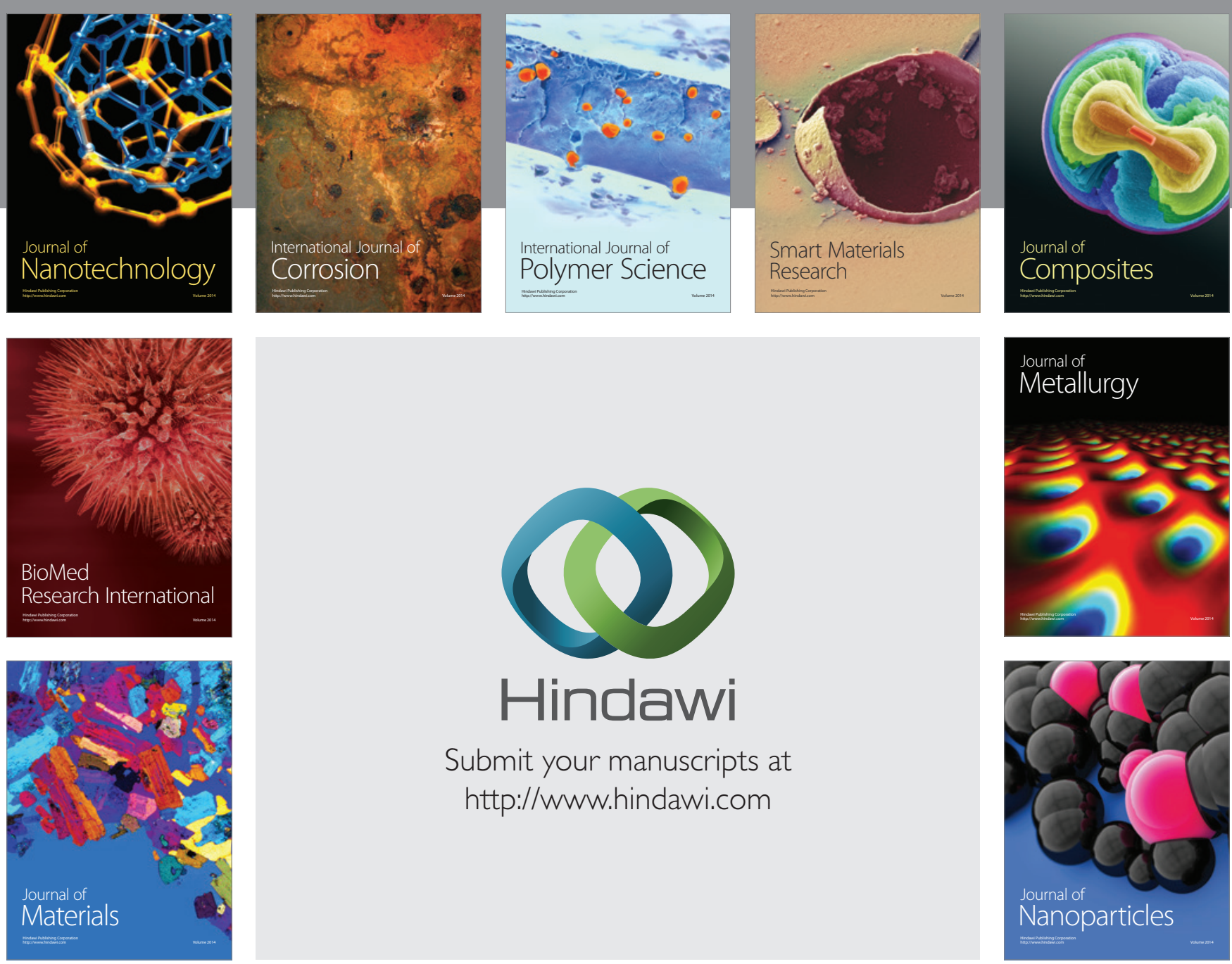

Submit your manuscripts at http://www.hindawi.com
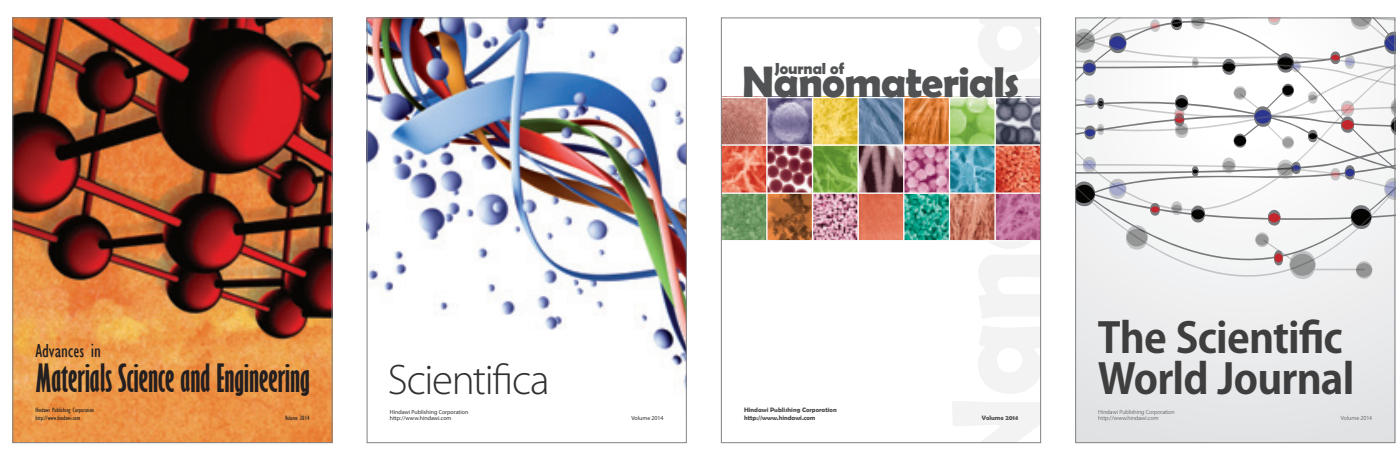

\section{The Scientific World Journal}
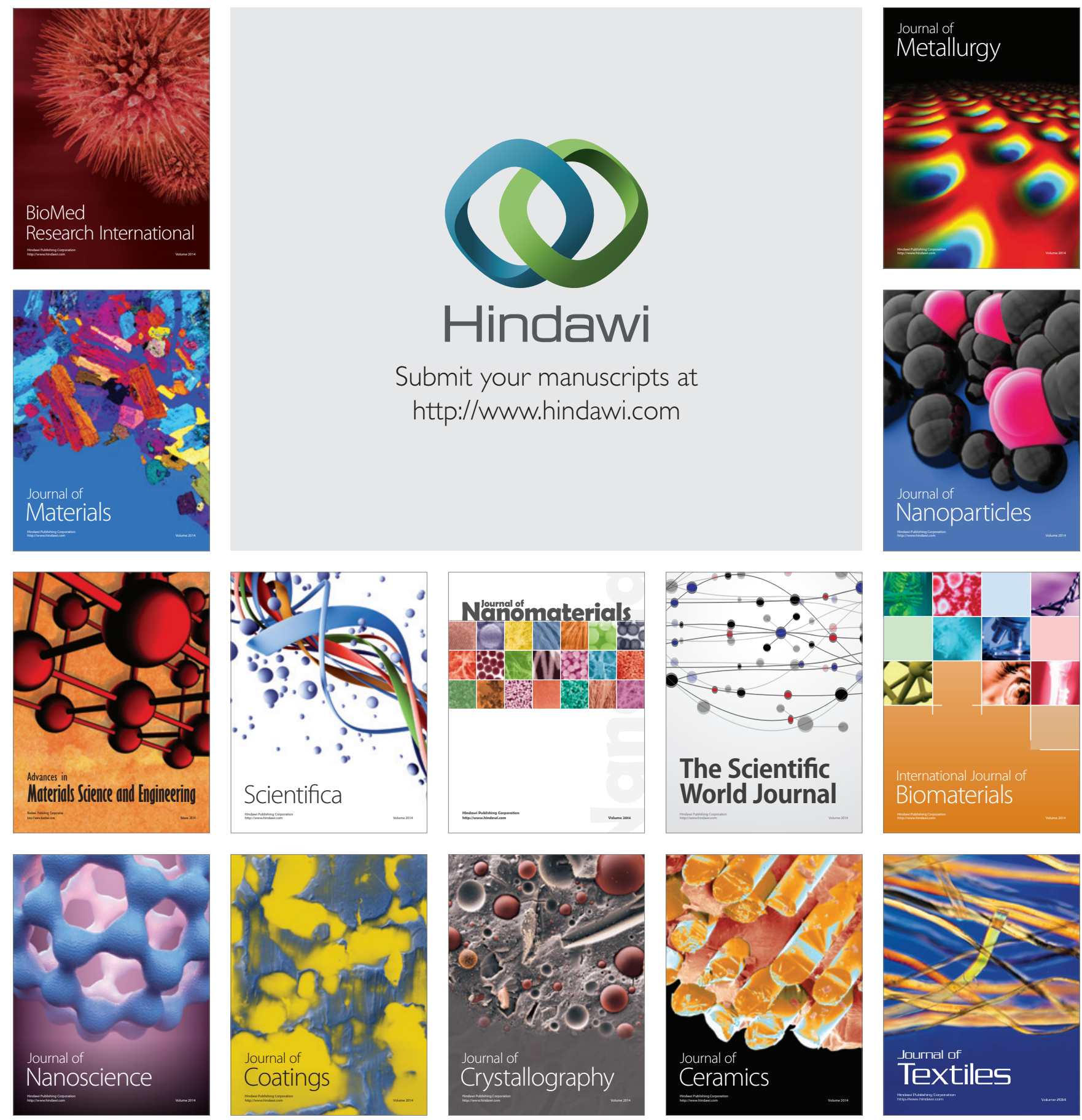